\title{
Illustrations and Tables
}

\section{Figures}

I. Predicted likelihood of two-month survival, several days before death from heart failure or lung cancer

2. Ultimate options

3. Pattern of health-care expenditures across a person's life

4. Appropriate care near the end of life

5. Trajectories of eventually fatal chronic illnesses

6. Major medical conditions before death, for Medicare beneficiaries

7. Overview of the MediCaring strategy

\section{Tables}

I. Top ten causes of death, 1900 and 2000

2. Priority care needs for the three illness trajectories

3. How the money moves

4. Summary of Research and Demonstration Provisions in the Proposed "Living Well with Fatal Chronic Illness Act of 2003" 
This page intentionally left blank 